\title{
イセエビの活動性と水中放射照度との関係について
}

\author{
久保伊津男 - 石渡 直 典 \\ (1964 年 7 月 21 日受理)
}

\section{ON THE RELATIONSHIP BETWEEN ACTIVITY OF JAPANESE SPINY LOBSTER AND UNDER WATER LIGHT INTENSITY}

\author{
Itsuo KuBo and Naonori IsHWata*
}

\begin{abstract}
It has been known $n^{1 / 3)}$ that the lobster has a crepuscular type of daily activity with two peaks in catch. But the mechanism for the bimodality of the activity is yet unknown.

In the present investigation, catch experiments and measurements of under water light intensity in the fishing ground of the lobster were carried out simultaneously, and an analysis was made with regard to the relationship between the activity and the light intensity. The results of the experiments are given in Table 3, and Fig. 2. Basing upon the results obtained from the present experiments, it may be said that the mechanism in question is as follows:sudden changes of the under water light intensity in dawn or dusk give stimulus for activity of the lobster, and consequently increase the catch of the lobster (Fig. 2).

Under water light intensity ranges $2.4 \sim 3.5 \times 10^{-4}$ and $2.2 \sim 2.8 \times 10^{-4} \mu \mathrm{W} / \mathrm{cm}^{2}$ in full moon night (moon-age 15) and new moon night (moon-age 4.3 ) respectively.
\end{abstract}

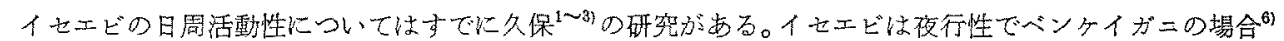

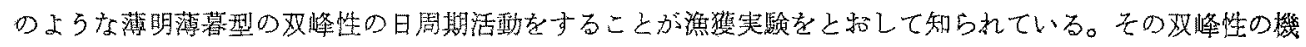

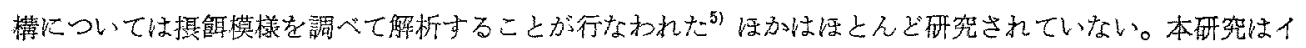

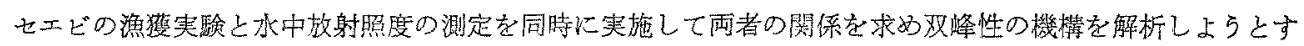
るものである。

本交に入るに先だも，この実䮖に祭して症々御援助をいただいた東京水産大学の左々㥙忠教授, 理化学

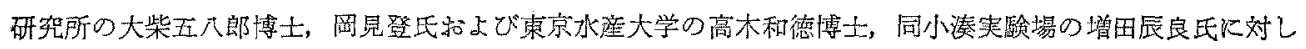
て深く感謝する。な叔本研究は文部省の科学研究頗の援助によるものである。

\section{実 験 方 法}

昭和 37 年 (1962) の9月 14 15 日の淦月時（月路 15 16）と同年 10 月 $3 \sim 4$ 日の新月時（月路 4.3

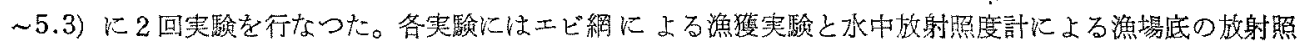
度測定を同時に行なつた。

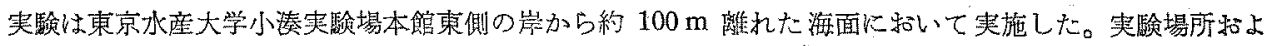

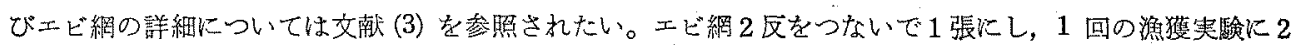
張を使用した。最初午前 8 時に網を 2 張東西方向に投入し, 10 時にこれを取り揚げるとともに他の 2 張を投 入し，これ以後は各偶数時に上記と同様な操作を繰返し行なつて実験開始の翌日の午前 8 時なでに, 第 1 回, 第 2 回の実験之もに各回 12 回の取り揚げを行なつた。

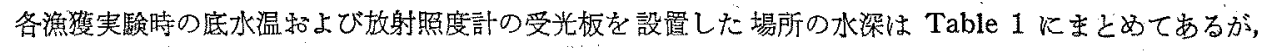

* 東京水産大学資源学教室 (Lab. Fish. Biol., Tokyo Univ. Fish., Shiba Kaigandori 6, Minato-ku, Tokyo, Japan). 
Table 1. Oceanographical data in the experiments. $\mathrm{W} \mathrm{T}$, water temperature; $\mathrm{D} \mathrm{W}$, depth of water.

\begin{tabular}{|c|c|c|c|c|c|}
\hline \multicolumn{3}{|c|}{$\begin{array}{c}\text { Exper. No. } 1 \\
\text { Sept. } 14 \sim 15,1962 ; \\
\text { moon-age, } 15 \sim 16\end{array}$} & \multicolumn{3}{|c|}{$\begin{array}{c}\text { Exper. No. } 2 \\
\text { Oct. } 3 \sim 4,1962 ; \\
\text { moon-age, } 4.3 \sim 5.3\end{array}$} \\
\hline $\begin{array}{l}\text { Hour } \\
\text { of day }\end{array}$ & $\begin{array}{c}\text { Bottom } \\
\text { W }{ }^{2}\left({ }^{\circ} \mathrm{C}\right)\end{array}$ & $\begin{array}{c}\mathrm{D} \mathrm{W} \\
(\mathrm{m})\end{array}$ & $\begin{array}{l}\text { Hour } \\
\text { of day }\end{array}$ & $\begin{array}{l}\text { Bottom } \\
\text { W T }\left({ }^{\circ} \mathrm{C}\right) \\
\end{array}$ & $\begin{array}{l}\text { D W } \\
(\mathrm{m})\end{array}$ \\
\hline 800 & 26.1 & 1.9 & 8 & 24.2 & 2.6 \\
\hline 1054 & 26.4 & 1.4 & 10 & 24.4 & 2.2 \\
\hline 1706 & 26.3 & 2.9 & 12 & 25.0 & 2.0 \\
\hline 2258 & 26.0 & 1.8 & 14 & 24.9 & 1.9 \\
\hline \multirow[t]{8}{*}{450} & 24.9 & 3.0 & 16 & 24.7 & 2.3 \\
\hline & & & 18 & 24.3 & 2.5 \\
\hline & & & 20 & 24.3 & 2.4 \\
\hline & & & 22 & 23.8 & 2.2 \\
\hline & & & 24 & 24.1 & 1.7 \\
\hline & & & 2 & 24.0 & 1.7 \\
\hline & & & 4 & 24.0 & 2.0 \\
\hline & & & 6 & 23.8 & 2.3 \\
\hline
\end{tabular}

第 1 回実験では底水温は $24.9 \sim 26.4^{\circ} \mathrm{C}$, 水深は $1.4 \sim 3.0 \mathrm{~m}$, 第 2 回実験ではそれ ぞれ 23.8 25. $0^{\circ} \mathrm{C}, 1.7 \sim 2.6 \mathrm{~m}$ である。 実鈳中は両回とも海は静かで風浪 1 であり， 天候も良く雲量はほとんど0であつた。

水中放射照度は理化学研究所製の水中放 射照度計を用いた (Fig. 1)。受光板は漁場 の西端に近い位置に設置し, フィルターに は緑色板 (MATSUDA VG-IA) を使用し た。

\section{実”験 結 果}

実験結果は Table 2 扝よび Fig. 2 に まとめてある。漁獲成績の時間的な变化は Table 2 にみると呿りであるが，傾向的に は過去の実験成績と全く一致している。

満月時には $18 \sim 22$ 時特よび $2 \sim 6$ 時に漁 獲尾数の峰がありそのモードは $20 \sim 22$ 時

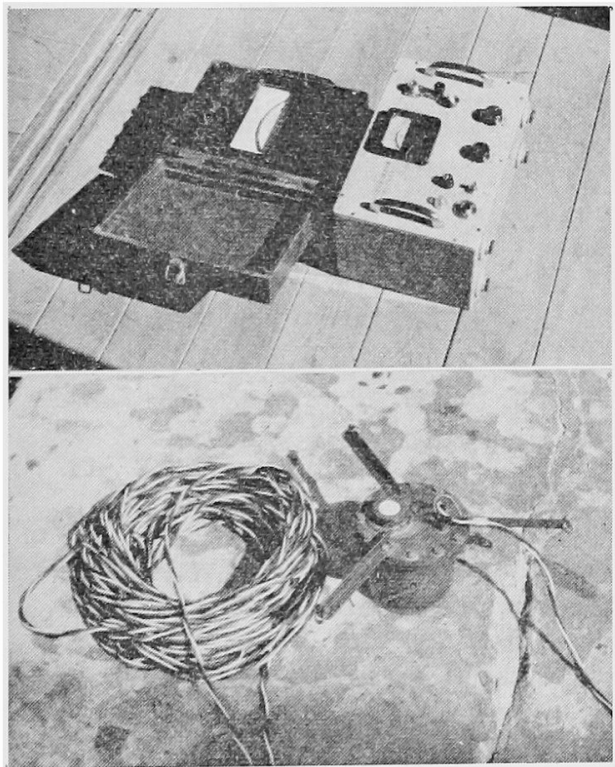

Fig. 1. Showing apparatus used for measurement of under water light intensity. 括よび 2 4 時にある。新月時には 18 20 時呿よ び 4〜6 時にモードのある 2 峰がみられ，この場合 の $2 \sim 4$ 時の漁獲尾数はその前の $22 \sim 24$ 時, $24 \sim$ 2 時の場合よりも多いが目立つて多くはない。両者 の平均值では 18 20 時と $4 \sim 6$ 時に峰が2又られ各 峰のモードもそれぞれその位置にある。

水中放射照度の測定結果は Table 3, 特よび Fig. 2 に示してあると拈りである。9 月 14 日の満月の 夜は雲がほとえどなく氷中放射照度の测定にはきわ めて好都合であつた。

満月時には水中放射照度は 18 時 11 分に $16.0 \times$ $10^{-4} \mu \mathrm{W} / \mathrm{cm}^{2 *} に$ にり, 同 15 分には半減し, 同 20 分には 4.9 に，30 分には 3.2 まで急激に下り，そ れ以降翌朝の 4 時 30 分までは 2.4 3.5 の閒をわ ずかに変化する程度で安定した放射照度を示した。 それ以後放射照度は急速に上年し，4 時 50 分には 6.8, 同 54 分には 12.0 に增加した (Fig. 2)。

新月時には 17 時 42 分に水中放射照度は 16.0 , 45 分に 8.8, 50 分に 4.5, 18 時に 2.8 と急に下 り，それ以後翌朝 5 時までは $2.2 \sim 2.8$ の間をわず かに上下する程度で安定した照度を示した。それ以 後放射照度は急に上り 5 時 10 分には $3.4 ， 15$ 分には 6.0, 20 分には 15.0 に上年した (Fig. 2)。

\footnotetext{
* 以下単に 16.0 と記载する。
} 
Table 2. Number of individuals caught in each experiment. Exper. No. 1 and No. 2 carried out on Sept. $14 \sim 15$ and Oct. $3 \sim 4,1962$ respectively.

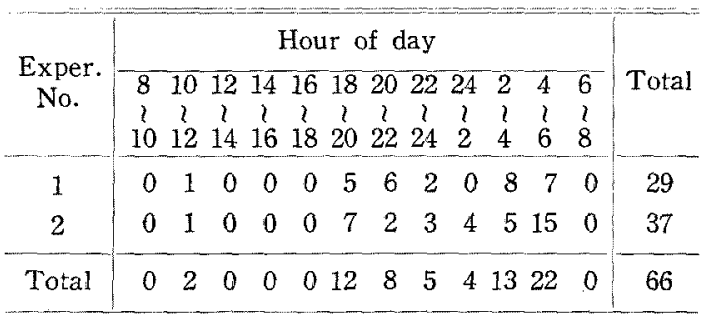

\section{漁獾量と水中放射照度との関係}

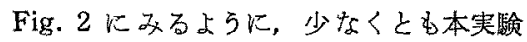
結果の示吉籍田内で判断すると，水中放射照 度の急激な変化がイセエビの活勤性を刺激し， その結果两維数が增してその時間区分内に漁 獲量の路が生ずるもののようで，摄慨律とは あまり密接な関係はみられないことはすで のベだ)と括りである。

夕方の場合 16 18 時の間, すなるちをだ 放射照度が昼間をあまり変放らない程度に高

Table 3. Under water light intensity in the two experiments.

$a$, the moonrise; $b$, the moonset.

\begin{tabular}{|c|c|c|c|c|c|}
\hline Day and & hour & $\begin{array}{l}\text { Under water } \\
\text { light intensity } \\
\left(\mu \mathrm{W} / \mathrm{cm}^{2}\right)\end{array}$ & Day and & hour & $\begin{array}{c}\text { Under water } \\
\text { light intensity } \\
\left(\alpha W / \mathrm{cm}^{2}\right)\end{array}$ \\
\hline \multirow[t]{14}{*}{$\begin{array}{l}1962 \\
\text { Sept. 14, }\end{array}$} & 1811 & $16.0^{\times 10^{-4}}$ & $\begin{array}{c}1962 \\
\text { Oct. } 3,\end{array}$ & 1742 & $16.0^{\times 10^{-4}}$ \\
\hline & 15 & 8.0 & & 45 & 8.8 \\
\hline & 20 & 4.9 & & 50 & 4.5 \\
\hline & $30 a$ & 3.2 & & $1800 \mathrm{a}$ & 2.8 \\
\hline & 1900 & 2.9 & & 30 & 2.4 \\
\hline & 30 & 3.0 & & 1900 & 2.5 \\
\hline & 2000 & 3.0 & & 30 & 2.4 \\
\hline & 30 & 3.2 & & 2000 & 2.2 \\
\hline & 2100 & 3.4 & & 30 & 2.3 \\
\hline & 30 & 3.4 & & 2100 & 2.3 \\
\hline & 2200 & 3.5 & & 30 & 2.3 \\
\hline & 30 & 3.5 & & 2200 & 2.4 \\
\hline & 2300 & 3.5 & & 30 & 2.4 \\
\hline & 30 & 3.4 & & 23.00 & 2.4 \\
\hline \multirow[t]{15}{*}{ Sept. 15, } & 000 & 3.2 & . & 30 & 2.4 \\
\hline & 30 & 3.5 & Oct. 4, & 000 & 2.3 \\
\hline & 100 & 3.2 & & 30 & 2.4 \\
\hline & 30 & 3.2 & & 100 & 2.3 \\
\hline & 200 & 3.1 & & 30 & 2.3 \\
\hline & 30 & 3.1 & & 200 & 2.3 \\
\hline & $300 \mathrm{~b}$ & 3.0 & & 30 & 2.4 \\
\hline & 30 & 2.7 & & 300 & 2.4 \\
\hline & 400 & 2.4 & & 30 & 2.3 \\
\hline & 30 & 2.6 & & 400 & 2.4 \\
\hline & 45 & 3.8 & & 30 & 2.3 \\
\hline & 50 & 6.8 & & 500 & 2.5 \\
\hline & \multirow[t]{3}{*}{54} & 12.0 & & 10 & 3.4 \\
\hline & & & & 15 & 6.0 \\
\hline & & & & 20 & 15.0 \\
\hline
\end{tabular}


い間は水中放射照度も高いために漁獲量は0であるが，つぎの 2 時間（18２0時）には満月時には 18 時 30

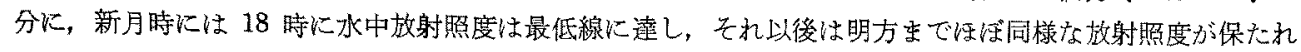
るわけで，この水中放射照度が急激に落らるとさにエビの活勘性が刺激され，政絸数が增加するょうである。

明方の埸合は放射照度が逆に急に上界するのであるが，その恋化がエビの活動性を刺激して罹網数が增加 するのであるらと考方られる。水中放射照度は満月時には 4 時 30 分，新月時に恃 5 時ずると急激に上年

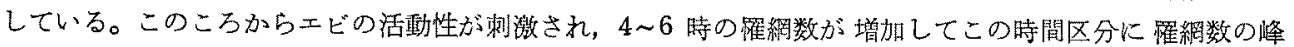

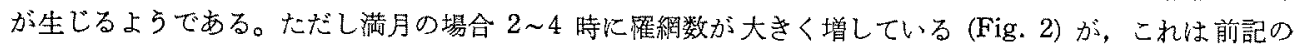
説明では了解できない。

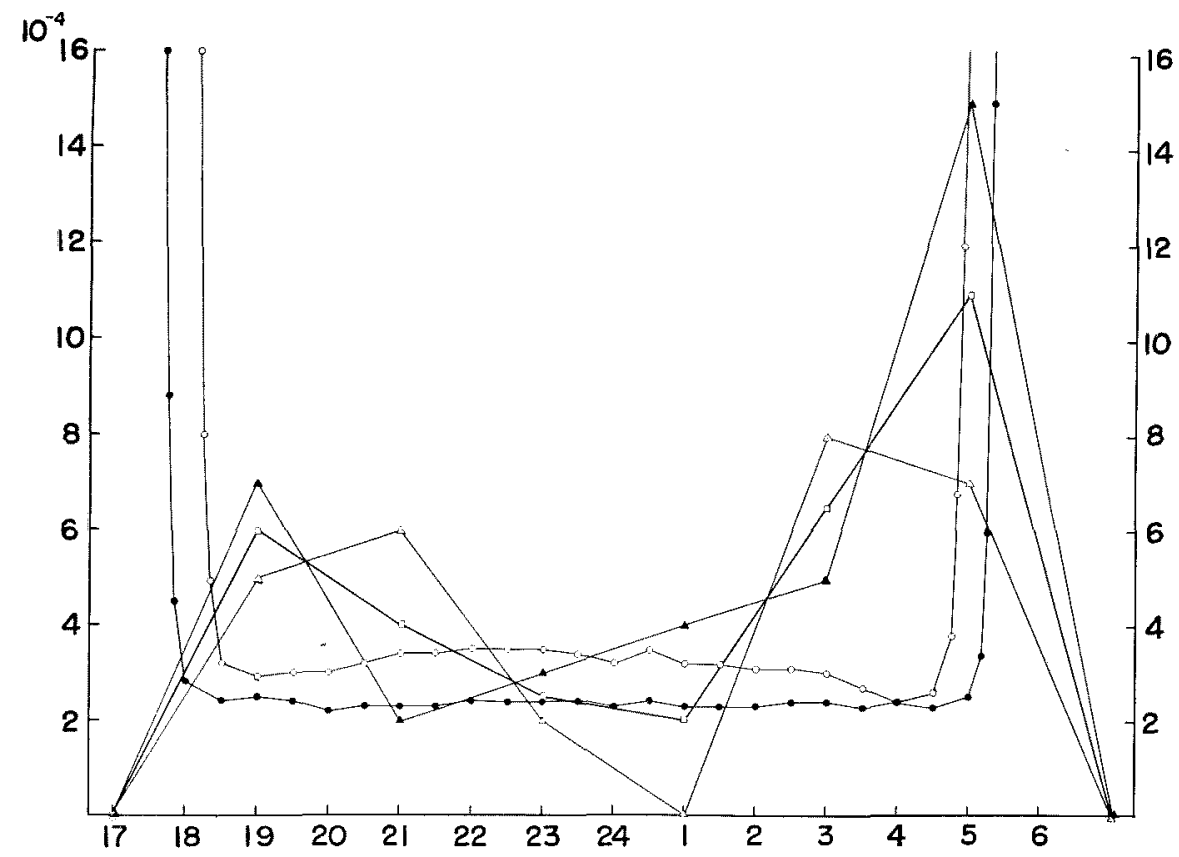

Fig. 2. Showing the relationship between catches (triangles and quadrates) and under water light intensity (circles). Right ordinate, number of individuals of the lobster caught in the catch experiments. Left ordinate, under water light intensity $\left(\mu \mathrm{W} / \mathrm{cm}^{2}\right)$. Abscissa, hour of day.

Soft and solid triangles and quadrates, changes in number of the lobster caught on Sept. 14 15, '62 (full moon), Oct. 3 4, '62 (new moon), and change of average number of the lobster caught in these two catch experiments respectively. Circles, change of under water light intensity; soft circles, full moon; solid ones, new moon.

論議

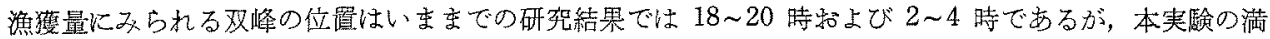
月時の場合の第 1 峰，および新月時の場合の第 2 峰はそれぞれいままでの結果と一致していない。その原因

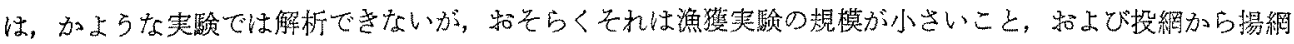
までの時間が 2 時閐といら相当長い時間であることなどに帰されよら。

水中放射照度は朝，夕，夜間ともに満月時に高い值が得られた。満月時に新月時よりも离い值が得られた 
のは測定の㭙季が前者は 9 月，啳者は 10 月であるから満月時に燷いのは当然であるう。夜間水中放射照度 が安定している間の放射照度は満月時が $2.4 \sim 3.5$ であり, 新月時が $2.2 \sim 2.8$ で振れの㬏忟後者の場合が やや小さいが，水中放射照度々のものは夜間を通じて前者の場合が $0.8 \sim 1.2$ 程度高い(Table 3)。これは 月光の影響であることは明らかで当然のことであるう。

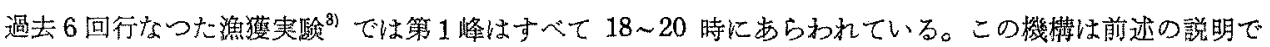

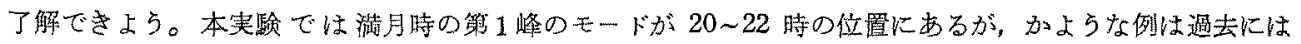
1954 年 7 月 $24 \sim 25$ 日の実剾の場合に得られている。モードの位置は实䮖に使用する網数の多宾, 刺激に 対するェビの活動性の持統の長短など支配されるものと考えられるから，モードの位置がずれているのは これらの条件の事情によるむのであるう。第 2 峰の場合は過去 6 回の実駰中 5 回はモードが $2 \sim 4$ 時に， 1

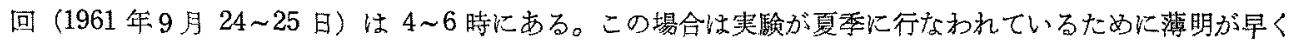

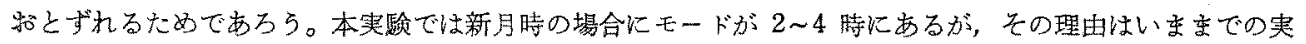
験結果では綐明し得ない。

\section{摘要}

（1）満月時（昭和 37 年 9 月 14 15 日，月龄 15）夜閏（18 時 30 分 4 時 30 分）千葉買安房郡天

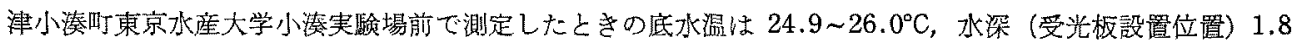
$\sim 3.0 \mathrm{~m}$ の場合の水中放射照度は $2.4 \sim 3.5 \times 10^{-4} \mu \mathrm{W} / \mathrm{cm}^{2}$ であつた。

（2） 新月時（昭和 37 年 10 月 3 4 日，月龄 4.3）夜間 (18 時 5 時) 上記の場所で測定したときの 底水温は $23.8 \sim 24.3^{\circ} \mathrm{C}$, 水深（同上） $1.7 \sim 2.5 \mathrm{~m}$ の場合の水中放射照度忙 $2.2 \sim 2.8 \times 10^{-4} \mu \mathrm{W} / \mathrm{cm}^{2}$ であ つた。

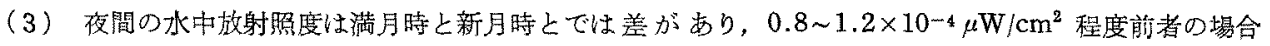
が大きい。

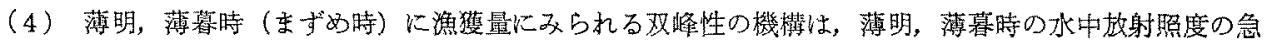

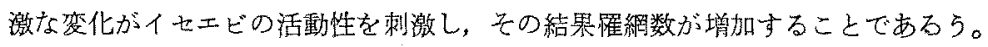

\section{文南戒}

1) 久保伊津男：水産增殖， 1 (1), 30 32 (1953).

2) KuBo, I.: Proceedings of Indo-Pacific Fish. Council 6th Session, Tokyo, Japan, Section III, pp. $387 \sim 398$ (1656).

3) 久保伊津男：本誌，28(3)，322 325 (1962).

4) - : 文部省研究報告集録 (昭 38), 農学編 (1), p. 218 (1963).

5) - 增田展良：本誌，30(1), 14 20 (1964).

6) 吉田元重：日本生態学会誌，11 (4), 160 162 (1961). 